\title{
Oral and pharyngeal cancers in Yemen: a retrospective study
}

E.S. Halboub, ${ }^{1,2}$ M.Abdulhuq ${ }^{7}$ and A. Al-Mandili ${ }^{3}$

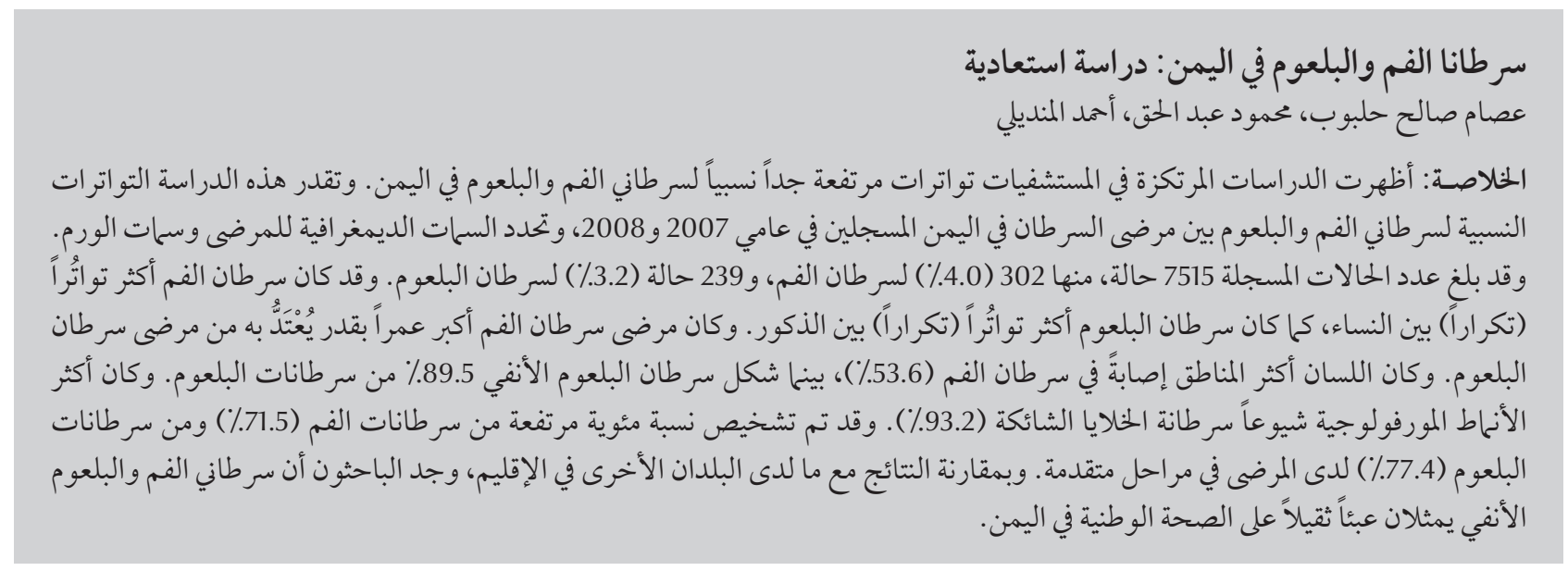

ABSTRACT Hospital-based studies have revealed very high relative frequencies of oral and pharyngeal cancers in Yemen. This study estimated the relative frequencies of oral and pharyngeal cancers among Yemeni cancer patients registered in 2007 and 2008 and determined patients' demographic and tumour characteristics. Of the registered 7515 cases, 302 (4.0\%) were oral cancer and 239 (3.2\%) pharyngeal cancer. Oral cancer was significantly more frequent among females while pharyngeal cancer was significantly more frequent among males. Oral cancer patients were significantly older than pharyngeal cancer patients. The tongue was the most affected oral site $(53.6 \%)$ while the nasopharynx comprised $89.5 \%$ of pharyngeal cancers. The most frequent morphological type was squamous cell carcinoma (93.2\%). High proportions of oral cancer (71.5\%) and pharyngeal cancer (77.4\%) patients were diagnosed at advanced stages. Compared with other countries in the region, oral cancer and nasopharyngeal cancer represent substantial national health burdens in Yemen.

\section{Cancers de la cavité buccale et du pharynx au Yémen : étude rétrospective}

RÉSUMÉ Des études en milieu hospitalier ont révélé des fréquences relatives très élevées du cancer oropharyngé au Yémen. La présente étude a estimé les fréquences relatives du cancer de la cavité buccale et du pharynx chez des patients yéménites atteints de cancers enregistrés en 2007 et 2008. Leurs données démographiques et les caractéristiques de leur tumeur ont été relevées. Sur 7515 cas enregistrés, 302 concernaient des cancers de la cavité buccale $(4,0 \%)$ et 239 des cancers du pharynx (3,2\%). Les cancers de la cavité buccale étaient nettement plus fréquents chez les femmes alors que les cancers du pharynx étaient beaucoup plus nombreux chez les hommes. Les patients atteints d'un cancer de la cavité buccale étaient bien plus âgés que les patients souffrant d'un cancer du pharynx. La langue était le site le plus souvent touché de la cavité buccale (53,6 \%) alors que le nasopharynx était impliqué dans 89,5\% des cancers du pharynx. Le type morphologique le plus fréquent était l'épithéliome malpighien (93,2\%). Des proportions élevées de patients atteints d'un cancer de la cavité buccale (71,5\%) ou du pharynx (77,4 \%) ont reçu un diagnostic à un stade avancé de la maladie. Par rapport à d'autres pays de la Région, le cancer de la cavité buccale et du nasopharynx représente une charge sanitaire importante pour le Yémen au niveau national.

'Department of Oral Medicine; ${ }^{3}$ Department of Oral Pathology, Faculty of Dentistry, University of Damascus, Damascus, Syrian Arab Republic (Correspondence to E.S. Halboub: helboub@yahoo.com).

${ }^{2}$ Department of Oral Medicine and Periodontology, Faculty of Dentistry, University of Sana'a, Sana'a, Yemen.

Received: 24/05/11; accepted: 26/07/11 


\section{Introduction}

Oral and pharyngeal cancers were estimated to affect more than 482000 people globally in 2008 , more than half of whom (273 000) died of the disease [1]. Unfortunately, two-thirds of these cases occurred in developing countries [2]. The prevalence of oral cancer and pharyngeal cancer shows a wide disparity by sex $[1,3]$ and geographical area $[3,4]$. While nasopharyngeal cancer is prevalent among the Chinese [5], oral cancer has been known to be prevalent in South Asian countries such as India [6] and Pakistan [7]. Worldwide variations in oral cancer distribution are believed to reflect different prevalences and patterns of risk habits such as khat chewing and waterpipe smoking [8-11].

Hospital-based studies have also revealed very high relative frequencies of oral cancer [12] and head and neck cancer $[13,14]$ in Yemen, where such risk habits are also common. As yet there has been no national population-based cancer report issued by the National Oncology Center (NOC) though many years have elapsed since its establishment in 2002. The objectives of this study therefore were to determine the relative frequency of oral cancer and pharyngeal cancer among Yemeni cancer patients who were registered at NOC in 2007 and 2008 and to analyse these patients by demographic and tumour characteristics.

\section{Methods}

This descriptive, epidemiological study was carried out on retrospective data provided by the NOC, Sana'a, Yemen. For all patients registered in 2007 and 2008, data regarding all patients with head and neck cancers was provided. The data included demographic details (sex, age and address) and tumour details (primary site, histology, grade and stage). The first author (H.E.) had access to the patients' hard files to validate the provided data. When there were discrepancies between data sources, the data in the hard files were used. The primary site (topography) and histology (morphology) of the neoplasms were reclassified and coded according to the International classification of diseases for oncology, 3rd edition (ICD-O-3) [15]. Hence only patients with malignant oral cancer or pharyngeal cancer (code C00-C14) were included in the present analysis. Tumours with other codes (i.e. not epithelial tumours) were excluded, even those affecting the oral cavity, pharynx or both sites. For the included cases, tumour staging was reclassified and coded according to the SEER summary staging manual 2000 [16]. The main morphology of the malignant tumours were reclassified further as: squamous cell carcinoma; adenoid cystic carcinoma; and papillary carcinoma. The less frequent morphological types were reclassified as other.

The statistical description and analyses were carried out using SPSS software, version 19. The descriptive statistics were presented as mean and standard deviation (SD) and relative frequencies as appropriate. The differences in age, were analysed by independent $t$-tests, while the associations of the cancer distribution (oral cancer versus pharyngeal cancer) with the different grouping factors were analysed using chi-squared tests. $P<0.05$ was taken as the level of significance.

\section{Results}

Of the 7515 patients registered with neoplasms in 2007 and 2008, 1004 (13.4\%) had head and neck cancers. Of these 541 were primary malignancies of the oral and pharyngeal tissues (code C00-C14); 302 (4.0\%) were oral cancer and $239(3.2 \%)$ pharyngeal cancer. Patients with tumours of the mesothelial and soft tissues (code C45-C49), lymphoid, haematopoietic and related tissues (C81-C96) and ill-defined secondary and unspecified sites (C76C80) were erroneously registered as oral cancer or pharyngeal cancer and were excluded $(n=110)$.

\section{Distribution by site}

The tongue was the most affected oral subsite (162/302, 53.6\%), followed by the floor of the mouth $(55 / 302,18.2 \%)$. Nasopharyngeal cancer constituted the major proportion of pharyngeal cancers $(214 / 239,89.5 \%)$ (Table 1).

\section{Distribution by region}

Of the 541 cases of oropharyngeal cancer $19.2 \%, 11.8 \%, 8.7 \%$ and $7.8 \%$ were referred from Al-Hodeida, Taiz, Hajja and Al-Amana provinces respectively (Table 2). The distribution of oral cancer and pharyngeal cancer was statistically different across different provinces $(P<0.001)$. Oral cancer was more frequent in Al-Hodeida, Hajja and Al-Mahweet provinces while pharyngeal cancer was more frequent in almost all other provinces.

\section{Distribution by age and sex}

The overall mean (SD) age of oropharyngeal cancer cases was 52.8 (SD 17.0) years. Although the difference in age between males and females within each cancer type was not significant, oral cancer patients (males, females or both) were significantly older than their pharyngeal cancer peers $(P<0.001)$ (Table 3).

More males were affected by all oropharyngeal cancers $(297,54.9 \%)$ than were females $(244,45.1 \%)$ (Table 1). The male to female ratios for oral cancer and pharyngeal cancer were 1.0 (152:150) and 1.5 (145:94) respectively. There was also a difference in the distribution of oral and pharyngeal cancers by sex. Women were more susceptible to oral cancer and males to pharyngeal cancer $(P=0.016)$ (Table 4). Neither the subsite distribution of oral cancer nor of pharyngeal cancer 
was significantly associated with patient's sex (Table 1).

One-quarter of oropharyngeal cancer patients $(135,25.0 \%)$ were aged $\leq 40$ years. Significantly more of this younger group had pharyngeal cancer than oral cancer, whereas among the older age group pharyngeal cancer was more common $(P<0.001)$ (Table 4$)$.

\section{Distribution by grade and stage}

It is noteworthy that all cases were histologically verified. The most frequent morphological type of oropharyngeal cancer was squamous cell carcinoma (93.2\%) and this was true for both oral and pharyngeal cases. The distribution by histological grade was significantly different; more of the well- and moderately-differentiated cancers were in oral cancer $(258 / 302,85.4 \%)$ compared with pharyngeal cancer $(32 / 239$ 13.4\%) $(P<0.001)($ Table 4$)$.

A high proportion of both oral (216, $71.5 \%)$ and pharyngeal $(285,77.4 \%)$ cancer patients were diagnosed at advanced (regional/metastasized) stages; however, the proportion of pharyngeal cancer patients at an advanced stage was significantly higher (Table 4$)(P<$ $0.001)$.

\section{Discussion}

The cancer registry is an essential part of any rational programme of cancer control, benefiting both individuals and the society in which they live. Establishing the NOC was therefore a big step towards improving cancer control in Yemen. Nevertheless, providing chemotherapy and radiotherapy to patients has been the main priority of the health service and the work of the registry centre has been neglected. Hence, many patients with early stage cancer or who had chemotherapy elsewhere might not have been recorded. Additionally, many cancer patients in Yemen still prefer to go abroad for treatment and are consequently not recorded. Therefore it would have been unreliable to attempt to calculate the cancer incidence in this study as it would have been an underestimate. The relative frequency is still a valid measure, however. The comparison of relative frequencies of a given cancer between populations is at best an indirect measure of the absolute risk difference and will be more reliable when the cancer site of interest accounts for a small proportion of all cancer cases [17] as it is the case in the present study.

Another limitation of the present study was the quality of the provided data. No data on patients' habits were available. Moreover, there was no standard coding and classification of tumour topography, morphology and extent of disease at the time of diagnosis. The authors, however, made efforts to compare the provided data with what was recorded in the patient's files and recoded them according to the international standards. In addition, all the registered cases were histologically verified which makes the present data reasonably valid and reliable.

The present analysis contradicts hospital-based studies which reported higher relative frequencies of oral cancer in the central and northern regions of Yemen: 18\% [12] and 8.7\% [14]. However, the figure in this study slightly exceeds what was previously reported in the southern region of Yemen: 2.9\% [18]. Such a regional disparity within an individual country was reported previously in Yemen [19] and Saudi

\begin{tabular}{|c|c|c|c|c|c|c|}
\hline \multirow[t]{2}{*}{ Cancer type } & \multicolumn{2}{|c|}{$\begin{array}{c}\text { Total } \\
(n=541)\end{array}$} & \multicolumn{2}{|c|}{$\begin{array}{c}\text { Males } \\
(n=297)\end{array}$} & \multicolumn{2}{|c|}{$\begin{array}{l}\text { Females } \\
(n=244)\end{array}$} \\
\hline & No. & $\%$ & No. & $\%$ & No. & $\%$ \\
\hline \multicolumn{7}{|l|}{ Oral cancer } \\
\hline Lip & 36 & 6.7 & 19 & 6.4 & 17 & 7.0 \\
\hline Tongue & 162 & 29.9 & 88 & 29.6 & 74 & 30.3 \\
\hline Gum & 37 & 6.8 & 15 & 5.1 & 22 & 9.0 \\
\hline Floor of mouth & 55 & 10.2 & 27 & 9.1 & 28 & 11.5 \\
\hline Other \& unspecified parts of the mouth & 3 & 0.6 & 0 & 0.0 & 3 & 1.2 \\
\hline Parotid gland & 3 & 0.6 & 0 & 0.0 & 3 & 1.2 \\
\hline Other \& unspecified major salivary glands & 6 & 1.1 & 3 & 1.0 & 3 & 1.2 \\
\hline Subtotal & 302 & 55.9 & 152 & 51.2 & 150 & 61.4 \\
\hline \multicolumn{7}{|l|}{ Pharyngeal cancer } \\
\hline Tonsil & 8 & 1.5 & 4 & 1.3 & 4 & 1.6 \\
\hline Nasopharynx & 214 & 39.6 & 134 & 45.1 & 80 & 32.8 \\
\hline Hypopharynx & 17 & 3.1 & 7 & 2.4 & 10 & 4.1 \\
\hline Subtotal & 239 & 44.2 & 145 & 48.8 & 94 & 38.5 \\
\hline
\end{tabular}




\begin{tabular}{|c|c|c|c|c|c|c|}
\hline \multirow[t]{2}{*}{ Province } & \multicolumn{2}{|c|}{$\begin{array}{c}\text { Total } \\
(n=541)\end{array}$} & \multicolumn{2}{|c|}{$\begin{array}{l}\text { Oral cancer } \\
(n=302)\end{array}$} & \multicolumn{2}{|c|}{$\begin{array}{l}\text { Pharyngeal cancer } \\
\qquad(n=239)\end{array}$} \\
\hline & No. & $\%$ & No. & $\%$ & No. & $\%$ \\
\hline Al-Hodaida & 104 & 19.2 & 76 & 25.2 & 28 & 11.7 \\
\hline Taiz & 64 & 11.8 & 30 & 9.9 & 34 & 14.2 \\
\hline Hajja & 47 & 8.7 & 36 & 11.9 & 11 & 4.6 \\
\hline $\mathrm{lbb}$ & 32 & 5.9 & 16 & 5.3 & 16 & 6.7 \\
\hline Al-Amana & 42 & 7.8 & 12 & 4.0 & 30 & 12.6 \\
\hline Sana'a & 36 & 6.7 & 14 & 4.6 & 22 & 9.2 \\
\hline Dhamar & 35 & 6.5 & 20 & 6.6 & 15 & 6.3 \\
\hline Amran & 31 & 5.7 & 12 & 4.0 & 19 & 7.9 \\
\hline Al-Mahweet & 28 & 5.2 & 20 & 6.6 & 8 & 3.3 \\
\hline Aden & 19 & 3.5 & 12 & 4.0 & 7 & 2.9 \\
\hline Other provinces & 103 & 19.0 & 54 & 17.9 & 49 & 20.5 \\
\hline Total & 541 & 100.0 & 302 & 25.2 & 239 & 11.7 \\
\hline
\end{tabular}

Chi-squared test, $P<0.001$.

Arabia [20]. In support of GLOBOCAN estimations [21] and other reports $[3,22-24]$, the relative frequency of oral cancer in Yemen was higher compared with many other developed countries and indeed other Arab countries. However, it was still much lower compared with data from Myanmar [25], Pakistan [7] and India [26]. The widespread habit of betel quid chewing within Asian populations, in addition to smoking tobacco, alcohol consumption and poor oral hygiene, have been associated with high incidences of oral cancer $[8,9]$. Chewing khat, smokeless tobacco use (locally known as shamma) and waterpipe smoking (locally known as mada'a) are widely prevalent in Yemen and have been linked with oral cancer $[10,11]$. Further research on this is needed in Yemen.
Unexpectedly, the relative frequency of pharyngeal cancer was higher compared with other reports from Yemen $[12-14,18]$ and other countries [7,23-29]. Nasopharyngeal cancer, which accounted for more than $89 \%$ of the pharyngeal cancers in the present study, is relatively common among Iraqi [21] and western North African men [30] and among the Chinese [5]. It is not considered to be a tobacco-related cancer [27]. However, genetic and infectious etiologies have been suggested [31].

In agreement with reports from Yemen [12,18,19], Saudi Arabia [23], Kuwait [27], Myanmar [25] and many other developed and developing countries [3], the tongue was the most affected oral subsite in men and women. Differences between regions have been reported however. In south central Asia, the buccal mucosa was the most affected site and this is consistent with being the site where betel quid is held when chewing $[3,26,32]$. In Iraq, the lip is reported to be the most affected oral site $[33,34]$, while the gingiva is the predominant oral site in Zimbabwe [35]. Although it is not the main site in direct contact with khat, shamma or both, the tongue is considered to be a high-risk site for oral cancer [36].

To the best of our knowledge, this was the first study which reported the distribution of oral cancer and pharyngeal cancer among different provinces in Yemen. Relative to pharyngeal cancer, oral cancer was significantly more common in Al-Hodeida, Hajja and Al-Mahweet provinces. Interestingly these areas are those where shamma

\begin{tabular}{lccccc}
\hline \multicolumn{7}{l}{ Table 3 Distribution of $\mathbf{5 4 1}$ cases of oral cancer and pharyngeal cancer by mean age and sex } \\
$\begin{array}{l}\text { Sex } \\
\text { No. of cases }\end{array}$ & $\begin{array}{c}\text { Mean (SD) age } \\
\text { (years) }\end{array}$ & $\begin{array}{c}\text { Pharyngeal cancer } \\
\text { No. of cases }\end{array}$ & $\begin{array}{c}\text { Mean (SD) age } \\
\text { (years) }\end{array}$ \\
Male & 152 & $59.5(15.5)$ & 145 & $45.9(14.9)$ & $<0.001$ \\
Female & 150 & $57.3(12.9)$ & 94 & $45.3(17.2)$ & $<0.001$ \\
Total & 302 & $58.4(14.3)$ & 239 & $47.7(17.6)$ & $<0.001$ \\
\hline
\end{tabular}

Independent t-test.

$S D=$ standard deviation . 


\begin{tabular}{|c|c|c|c|c|c|c|c|}
\hline \multirow[t]{2}{*}{ Variable } & \multicolumn{2}{|c|}{$\begin{array}{c}\text { Total } \\
(n=541)\end{array}$} & \multicolumn{2}{|c|}{$\begin{array}{l}\text { Oral cancer } \\
\quad(n=302)\end{array}$} & \multicolumn{2}{|c|}{$\begin{array}{l}\text { Pharyngeal cancer } \\
\qquad(n=239)\end{array}$} & \multirow[t]{2}{*}{$P$-value } \\
\hline & No. & $\%$ & No. & $\%$ & No. & $\%$ & \\
\hline \multicolumn{8}{|l|}{ Age group (years) } \\
\hline$\leq 40$ & 135 & 25.0 & 46 & 15.2 & 89 & 37.2 & \multirow[t]{2}{*}{$<0.001$} \\
\hline$>40$ & 406 & 75.0 & 256 & 84.8 & 150 & 62.8 & \\
\hline \multicolumn{8}{|l|}{ Sex } \\
\hline Male & 297 & 54.9 & 152 & 50.3 & 145 & 60.7 & \multirow{2}{*}{0.016} \\
\hline Female & 244 & 45.1 & 150 & 49.7 & 94 & 39.3 & \\
\hline \multicolumn{8}{|l|}{ Main morphology } \\
\hline Squamous cell carcinoma & 504 & 93.2 & 281 & 93.0 & 223 & 93.3 & \multirow{4}{*}{$>0.05$} \\
\hline Adenoid cystic carcinoma & 9 & 1.7 & 6 & 2.0 & 3 & 1.3 & \\
\hline Papillary carcinoma & 12 & 2.2 & 8 & 2.6 & 4 & 1.7 & \\
\hline Other & 16 & 3.0 & 7 & 2.3 & 9 & 3.8 & \\
\hline \multicolumn{8}{|l|}{ Grade } \\
\hline Well differentiated & 224 & 41.4 & 211 & 69.9 & 13 & 5.4 & \multirow{5}{*}{$<0.001$} \\
\hline Moderately differentiated & 66 & 12.2 & 47 & 15.6 & 19 & 7.9 & \\
\hline Poorly differentiated & 29 & 5.4 & 17 & 5.6 & 12 & 5.0 & \\
\hline Undifferentiated & 114 & 21.1 & 7 & 2.3 & 107 & 44.8 & \\
\hline Unspecified & 108 & 20.0 & 20 & 6.6 & 88 & 36.8 & \\
\hline \multicolumn{8}{|l|}{ Tumour extension (stage) } \\
\hline Localized & 34 & 6.3 & 30 & 9.9 & 4 & 1.7 & \multirow[t]{4}{*}{$<0.001$} \\
\hline Regional & 334 & 61.7 & 193 & 63.9 & 141 & 59.0 & \\
\hline Metastasized & 67 & 12.4 & 23 & 7.6 & 44 & 18.4 & \\
\hline Unspecified & 106 & 19.6 & 56 & 18.5 & 50 & 20.9 & \\
\hline
\end{tabular}

${ }^{a}$ Chi-squared test.

use and waterpipe smoking are known to be widely prevalent. As no data on substance use habits were available, future research could investigate whether these habits are associated more with oral cancer than pharyngeal cancer.

Both sexes in this study were found to be affected equally by oral cancer. Previous reports from Yemen $[13,14,18]$ and other countries $[3,7,23-26,34]$ found a higher relative frequency of oral cancer among men. However, Sawair et al. reported a higher relative frequency of oral cancer among women in Yemen [12]. Cultural norms allow more men to be exposed to risk factors for oral cancer such as smoking, khat and shamma compared with women and this is an area for future research. In agreement with studies in Yemen $[12-14,18]$ and other countries [7,23-26,29], men more commonly were affected by pharyngeal cancer than were women. It is difficult at present to suggest reasons to explain the higher relative frequency of pharyngeal cancer (especially the nasopharyngeal cancer) among Yemeni men. However, face covers commonly worn by women in Yemen might protect them from infection by Epstein-Barr virus [31], which is considered as an etiological factor for nasopharyngeal cancer.

The mean age of oral cancer patients was comparable to those reported by previous studies in Yemen $[12,19]$ and Iraq [33]. However it was lower than reports from Saudi Arabia [37] and most developed countries [38], but higher than reported in Pakistan [32], Myanmar [25] and Zimbabwe [35]. This disparity could be reflected partly by the onset and the intensity of practising risk habits in different regions worldwide. On average, the khat chewing habit starts in the early 20s and the frequency of practising it ranges from once a week to daily. Shamma use and waterpipe smoking, on the other hand, start at earlier ages and may be practised more than once a day.

Patients were affected by pharyngeal cancer at a significantly younger age compared with oral cancer. Moreover, more than $37 \%$ of patients with pharyngeal cancer were aged 40 years or less. The occurrence of pharyngeal cancer in younger age populations was reported too in Saudi Arabia [31] and Kuwait [27]. This might mean that the pharyngeal tissues are more susceptible or more exposed to risk factors or both.

In agreement with other studies in Pakistan [32], Myanmar [25] and Zimbabwe [35], squamous cell carcinoma 
was the most common morphologic type diagnosed in oral and pharyngeal cancers. Moreover, most oral cancer cases were graded well to moderate differentiation whereas most pharyngeal cancer cases were graded poor to undifferentiated. In addition to being more accessible to diagnosis, the previously mentioned findings might explain the lower proportion of oral cancer with advanced stage (regional and distant metastasis) compared with pharyngeal cancer. Unfortunately, only $9.9 \%$ and $1.7 \%$ of oral cancer and pharyngeal cancer cases respectively were diagnosed at the localized stage. These proportions might be underestimated; tumour stage was unknown in $18.5 \%$ and $20.9 \%$ of oral cancer and pharyngeal cancer cases respectively. Furthermore, many governmental and nongovernmental health facilities might not refer patients with early stage cancers to the NOC, leading to under-recording. However, patients' lack of awareness and health knowledge along with poor resources in primary and secondary health care are possible reasons that should not be overlooked.

A high relative frequency of pharyngeal cancer (especially nasopharyngeal) among Yemenis is noted here for the first time. Overall, nasopharyngeal cancer and oral cancer in Yemen represent national health burdens. Large-scale, matched case-control studies are needed to determine the risk factors for these cancers. The presence of a high quality national population-based cancer registry is the cornerstone to assess the burden of each site-specific cancer and to plan and direct the available health care resources and programmes accordingly.

\section{Acknowledgements}

Our special thanks go to all staff members of the National Oncology Center, Sana'a, Yemen for providing the raw data and for their efforts in facilitating the task of matching these data with the patient's hard files.

\section{References}

1. Ferlay J et al. Estimates of worldwide burden of cancer in 2008: GLOBOCAN 2008. International Journal of Cancer, 2010, 127:2893-2917.

2. Warnakulasuriya S. Global epidemiology of oral and oropharyngeal cancer. Oral Oncology, 2009, 45:309-316.

3. de Camargo Cancela $M$ et al. Oral cavity cancer in developed and in developing countries: population-based incidence. Head and Neck, 2010, 32:357-367.

4. GLOBOCAN 2002: Cancer incidence, mortality and prevalence worldwide. IARC CancerBase No. 5, version 2.0. Lyon, International Agency for Research on Cancer, 2004.

5. Warnakulasuriya KA et al. Cancer of mouth, pharynx and nasopharynx in Asian and Chinese immigrants resident in Thames regions. Oral Oncology, 1999, 35:471-475.

6. Sherin $\mathrm{N}$ et al. Changing trends in oral cancer. Indian Journal of Cancer, 2008, 45:93-96.

7. Bhurgri $Y$ et al. Cancer incidence in Karachi, Pakistan: first results from Karachi Cancer Registry. International Journal of Cancer, 2000, 85:325-329.

8. Nair $\mathrm{U}$, Bartsch $\mathrm{H}, \mathrm{Nair} J$. Alert for an epidemic of oral cancer due to use of the betel quid substitutes gutkha and pan masala: a review of agents and causative mechanisms. Mutagenesis, 2004, 19:251-262.

9. Rosenquist K. Risk factors in oral and oropharyngeal squamous cell carcinoma: a population-based case-control study in southern Sweden. Swedish Dental Journal. Supplement, 2005, 179:1-66.

10. Nasr AH, Khatri ML. Head and neck squamous cell carcinoma in Hajjah, Yemen. Saudi Medical Journal, 2000, 21:565-568.

11. Scheifele C, Nassar A, Reichart PA. Prevalence of oral cancer and potentially malignant lesions among shammah users in Yemen. Oral Oncology, 2007, 43:42-50.

12. Sawair FA et al. High relative frequency of oral squamous cell carcinoma in Yemen: qat and tobacco chewing as its aetiological background. International Journal of Environmental Health Research, 2007, 17:185-195.
13. Abdul-Hamid G et al. Pattern of head and neck cancer in Yemen. GulfJournal of Oncology, 2010, 7:21-24.

14. Al-Thobhani AK, Raja'a YA, Noman TA. The pattern and distribution of malignant neoplasms among Yemeni patients. Saudi Medical Journal, 2001, 22:910-913.

15. International classification of diseases for oncology, 3rd ed. Geneva, World Health Organization, 2000.

16. Young JL et al., eds. SEER summary staging manual-2000: codes and coding instructions. Bethesda, Maryland, National Cancer Institute, 2001 (NIH Pub. No. 01-4969).

17. Esteve J et al. Statistical methods in cancer research. Vol. IV: descriptive epidemiology. Lyon, International Agency for Research on Cancer, 1994.

18. Ba Saleem $\mathrm{HO}$ et al. Five years cancer incidence in Aden Cancer Registry, Yemen (2002-2006). Asian Pacific Journal of Cancer Prevention, 2010, 11:507-511.

19. Halboub $\mathrm{E}$ et al. A case series analysis of 248 oral cancers from Yemen. Oral Diseases, 2010, 16:536.

20. Brown A, Ravichandran K, Warnakulasuriya S. The unequal burden related to the risk of oral cancer in the different regions of the Kingdom of Saudi Arabia. Community Dental Health, 2006, 23:101-106.

21. GLOBECAN 2008. International Agency for Research on Cancer [online database] (http://www-dep.iarc.fr/, accessed 11 July 2012).

22. Rawashdeh MA, Matalka I. Malignant oral tumors in Jordanians, 1991-2001. A descriptive epidemiological study. International Journal of Oral and Maxillofacial Surgery, 2004, 33:183-188.

23. Registry SC. Cancer incidence report, Saudi Arabia 2006. Riyadh, Ministry of Health and Saudi Cancer Registry, 2006.

24. Jemal A et al. Cancer statistics, 2010. CA: a Cancer Journal for Clinicians, 2010, 60:277-300.

25. Oo $\mathrm{HN}$ et al. Oral cancer in Myanmar: a preliminary survey based on hospital-based cancer registries. Journal of Oral Pathology and Medicine, 2011, 40:20-26. 
26. Sen $U$ et al. Cancer patterns in eastern India: the first report of the Kolkata cancer registry. International Journal of Cancer, 2002, 100:86-91.

27. Morris RE et al. The epidemiology of lip, oral cavity and pharyngeal cancers in Kuwait 1979-1988. British Journal of Oral and Maxillofacial Surgery, 2000, 38:316-319.

28. Doobaree IU et al. Head and neck cancer in South East England between 1995-1999 and 2000-2004: an estimation of incidence and distribution by site, stage and histological type. Oral Oncology, 2009, 45:809-814.

29. Attar E et al. Head and neck cancer in a developing country: a population-based perspective across 8 years. Oral Oncology, 2010, 46:591-596.

30. Salim El et al. Cancer epidemiology and control in the Arab world - past, present and future. Asian Pacific Journal of Cancer Prevention, 2009, 10:3-16.

31. Andejani AA, Kundapur V, Malaker K. Age distribution of nasopharyngeal cancer in Saudi Arabia. Saudi Medical Journal, 2004, 25:1579-1582.

32. Bhurgri Y. Cancer of the oral cavity-trends in Karachi South (1995-2002). Asian Pacific Journal of Cancer Prevention, 2005, 6:22-26.
33. Al-Rawi NH, Talabani NG. Squamous cell carcinoma of the oral cavity: a case series analysis of clinical presentation and histological grading of 1,425 cases from Iraq. Clinical Oral Investigations, 2008, 12:15-18.

34. Al-Fouadi A, Parkin DM. Cancer in Iraq: seven years' data from the Baghdad Tumour Registry. International Journal of Cancer, 1984, 34:207-213.

35. Chidzonga MM, Mahomva L. Squamous cell carcinoma of the oral cavity, maxillary antrum and lip in a Zimbabwean population: a descriptive epidemiological study. Oral Oncology, 2006, 42:184-189.

36. Mashberg A, Samit A. Early diagnosis of asymptomatic oral and oropharyngeal squamous cancers. CA: a Cancer Journal for Clinicians, 1995, 45:328-351.

37. Allard WF, DeVol EB, Te OB. Smokeless tobacco (shamma) and oral cancer in Saudi Arabia. Community Dentistry and Oral Epidemiology, 1999, 27:398-405.

38. Quaglia A et al. A wide difference in cancer survival between middle aged and elderly patients in Europe. International Journal of Cancer, 2007, 120:2196-2201.

\section{Cancer survival in Africa, Asia, the Caribbean and Central America}

Population-based cancer survival rates offer an important benchmark for measuring a health care system s overall effectiveness in the fight against cancer. Cancer survival in Africa, Asia, the Caribbean and Central America presents in-depth cancer survival data from 27 population-based cancer registries in 14 low- and middle-resource countries.

The differences in cancer survival reported in populations observed between and within countries studied in this volume provide valuable insights for future planning and investment by governments in primary prevention activities, early detection initiatives and tertiary care to achieve meaningful cancer control.

Further information about this and other WHO publications is available at: http://www.who.int/publications/en/ 